\title{
The Intentional Versus the Propositional STRUCTURE OF CONTENTS
}

\author{
Wolfgang Spohn \\ Department of Philosophy \\ University of Konstanz. \\ 78457 Konstanz \\ Germany
}

\section{The Thesis*}

The mind is a representing organ. It is somehow able to receive, store, retrieve, and express content. The hallmark of contentfulness is given by propositional attitudes such as desiring, expecting, fearing, and hoping. I commit here the common sin of taking belief to be the paradigmatic attitude and pretending it to be representative of all the other ones; I shall leave this pretension unchecked.

The issue then is: how to characterize belief contents, the objects to which the believer stands in the belief relation? One or, perhaps, the standard account is to conceive of contents as sets of doxastic possibilities (where "doxastic" so far only signals that the possibilities are used to characterize belief). A content consists of those possibilities that may be true according to it and excludes all the others; a content is a truth condition.

So, what are doxastic possibilities? Traditionally, they were assumed to be possible worlds $w$; this is what I call the propositional conception of contents. Then it was discovered that this won't do, doxastic possibilities should rather be conceived as centered worlds, i.e., triples $\langle w, s, t\rangle$ consisting of a possible world $w$, an

\footnotetext{
* This is, in fact, my third attempt to explain and defend the thesis. In the first German version (Spohn 1997) the thesis was embedded in a number of general observations about epistemology. This attempt was reduced to its core in the second English version (Spohn 1998). The present version is updated in various respects and will put the emphasis on what I call the third argument (in section 5) that $\mathrm{I}$ had in mind from the beginning, but recognized only after the second version as being in the center of the dispute.
} 
object $s$ existing in $w$, and a time $t$ at which $s$ exists in $w$. This allows dealing with the attitudes de se and de nunc that were argued to be irreducible to strictly propositional attitudes.

My thesis will be that this still won't do. It will be that doxastic possibilities should be conceived as quadruples $\langle w, s, t, \mathbf{d}\rangle$, where $\langle w, s, t\rangle$ is a centered world and $\mathbf{d}=\left\langle d_{1}, d_{2}, \ldots\right\rangle$ is a (finite or infinite) sequence of objects existing in $w$. I call this the intentional conception of contents.

My terminology is perhaps not the happiest one; but I could not think of any better. It is unhappy, because the philosophical usage of "intentional", which is not the colloquial one, anyway, is at least ambiguous, an ambiguity originating from its modern founder Brentano (1874). In the wider sense, intentionality is just the distinctive feature of the mind. In that sense it is the directedness of the mind to something (external to it), its capacity to represent, to have or process contents, however they are conceived. In this sense, the propositional conception of contents is just one of several attempts to capture intentionality. There is, however, a narrower sense according to which intentionality more specifically denotes the directedness of the mind to (external) objects, something explicitly written into the intentional conception of contents in a way still to be uncovered, but not into the propositional conception that relates to (sets of) worlds and at best indirectly to objects insofar they may exist in worlds. In any case, it is this narrow sense that stands behind my terminological choice. ${ }^{1}$

My thesis may sound familiar, though perhaps unusually expressed. It is indeed essentially inspired by similar work, in particular by the path-breaking essays of Perry (1980), Kamp (1981), and Heim (1982). However, similar claims are usually embedded into an almost inextricable mixture of semantics and epistemology. By contrast, I intend the thesis to be a purely epistemological claim, and as such I have not seen it entertained in the literature.

\footnotetext{
${ }^{1}$ The following quotation nicely displays Brentano's thesis of intentionality as the defining characteristic of the mental as well as the ambiguity (note that „inexistence“, as it is used in the quote, does not mean ,non-existence“, but „existence in“): "Every mental phenomenon is characterized by what the Scholastics of the Middle Ages called the intentional (or mental) inexistence of an object, and what we might call, though not wholly unambiguously, reference to a content, direction toward an object, ... or immanent objectivity. Every mental phenomenon includes something as object within itself, although they do not all do so in the same way. In presentation something is presented, in judgement something is affirmed or denied, in love loved, in hate hated, in desire desired and so on. This intentional in-existence is characteristic exclusively of mental phenomena. No physical phenomenon exhibits anything like this. We can, therefore, define mental phenomena by saying that they are those phenomena which contain an object intentionally within themselves." (Brentano 1874/1973, pp. 88f. in the English translation.)
} 
Gaining a proper understanding of this contrast and thus of the thesis will require quite a lot of stage setting, disentangling, and explaining. This will take almost half of the paper, i.e., section 2 for stage setting of a more general kind and section 3 for deepening the specific dialectical background of the thesis. At the same time, this will elucidate the deep significance of my thesis.

I shall proceed with three arguments in favor of the thesis. I do not expect them to be conclusive; there hardly are conclusive arguments in philosophy. I hope, however, that they shift the balance of systematic reasons, strategic considerations, and aesthetic evaluations. More specifically, I advance two graphic arguments by way of example in section 4 . Not surprisingly, the arguments are not cogent, as is shown by an objection of Zimmermann (1999). This will shift the discussion to a strategic level in section 5. In various fields, not only the present one, there are those appealing to the so-called method of fine-grained descriptions in order to deal with problematic examples and those who find it more fruitful and illuminating to avoid this method. I shall argue for the latter position which, in the case at hand, means accepting the intentional conception of contents. This will be my third and main argument. The afterthoughts in section 6 will emphasize the relevance of my conclusion.

\section{Stage Setting}

In order to assess the significance of the thesis we have to disentangle belief from language in several respects. This will be hard work. It is peculiar: the linguistic turn has taught philosophy so much; at the same time, though, it has obstructed the view to pure epistemology, so much so that the latter may appear to be a phantom. It is not, I believe. So let us clear our view in six preliminary steps.

(1) There are, basically, two ways of characterizing objects of belief; they are, roughly, either identified with propositions (in an as yet unspecified sense) or with sentences. That is, characterizations of objects of belief may either focus on semantic aspects, on the fact that beliefs are true or false; or they may focus on the fact that beliefs have to have some encoding, some representational structure making them apt for computation. Quine is certainly the champion of the latter view, though on the ground of his denial of meanings, while the more recent defenders of the view focus on beliefs as representations in the mind/brain encoded 
in some way and possibly in the language of thought, however language-like that is. Let me put this view to one side, without much argument. ${ }^{2}$ It is simply that I am so much more impressed by the theoretical achievements of the broadly propositional view and do not see how the sentential view could ever compete with them. ${ }^{3}$ Thereby, we disentangle belief from morphosyntactic features of language.

(2) Propositions are usually explained to be sentence meanings. Therein, of course, lies the semantic entanglement of epistemology that is much harder to grapple with. It entails that there are about as many characterizations of belief contents within the broadly propositional view as there are theories of meaning. There are Fregean senses and thoughts ${ }^{4}$, Russellian singular and general propositions (cf. Russell 1910/11 and 1918/19), and Carnapian intensions (cf. Carnap 1947); there are Hintikka's (1962) model sets, Kaplan's (1977) characters, Stalnaker's (1978) propositional concepts and their diagonals, properties as conceived in Lewis (1979), the situations of Barwise and Perry (1981 and 1983, ch. 9-10) and various constructions thereof, and so forth.

This manifold is slightly confusing. There is, however, a common basic idea behind it, at least since Carnap (1947): namely the idea to characterize propositions and thus contents via the exclusion of possibilities. When I believe, for instance, that the sun will rise tomorrow I exclude all possible cases in which it does not rise. This is not to say that I admit all cases in which the sun does rise; my further beliefs exclude many of them as well. However, if we consider all of my beliefs and all the cases excluded by them we arrive at a positive rest embracing the cases I admit as possible. These cases are called my doxastic alternatives, a term coined by Hintikka (1962, p. 49), and the set consisting of all my doxastic alternatives is called my belief set, which is a subset of the set of all doxastic possibilities.

The characterization of contents explicitly forms the technical basis of the standard system of doxastic logic; according to it one believes each superset of

\footnotetext{
${ }^{2}$ Likewise, I shall ignore hybrid constructions like Carnap's suggestion in his $(1947, \S 14)$ to abstract objects of belief from intensional isomorphism, a suggestion profoundly elaborated by Bealer (1982).

${ }^{3}$ To give just one hint: Bayesianism, surely a great epistemological theory, is entirely built on the propositional view. I do not know of any workable probability theory defined for sentences and, that's essential, dispensing with intensionality, i.e., with the substitutivity of logical equivalents.

${ }^{4}$ Frege (1918) is a problematic case, though. Since the only identity criterion for thoughts, i.e., for sentence meanings, he actually gives is an epistemological one, one cannot say that semantics is prior to epistemology for Frege. Cf. Kemmerling (1990, pp. 161ff.)
} 
one's belief set, one disbelieves each set of possibilities disjoint with the belief set, and one is unopinionated about the rest. Consistency and deductive closure of beliefs is automatically built in into this account. Theories of graded beliefs, e.g., subjective probability theory, are based on the same idea. However, this idea is just a leitmotif. Due to its neutrality it seems to open a direct way to pure epistemology without semantic detour, but at the same time it hides the semantic entanglement we are in as badly as before.

(3) One way how language still creeps in is the characterization of (doxastic) possibilities or possible cases. When Carnap (1947) first implemented the basic idea he took possible cases to be state descriptions, linguistic entities. However, this made possibilities and thus belief too language-dependent. Speakers of different languages should be able to exclude the same cases, and there may be more possible cases to believe or to exclude than one is able to represent as a state description in a given vocabulary. Such problems suggest the conclusion that possible cases rather are complete possible worlds and not linguistically constituted in any way. Here I agree with the criticism in Lewis (1986a, ch. 3) of the various kinds of ersatzism. However, this leaves open so far whether we should understand possible worlds in a Wittgensteinian manner as in some sense maximal states of affairs, as repeatedly defended by Armstrong, e.g. in his (1997), or in a Lewisian manner as in some sense maximal individuals. ${ }^{5}$

The issue is pressing, and step (6) below makes sense only with respect to Lewisian possible worlds, which I am hence inclined to assume. However, this metaphysical issue is beyond the scope of this paper, and I would like to stay neutral. Indeed, my thesis will not be affected by the issue, as far as I see, and my arguments in its favor in section 4 and 5 work for both conceptions of possible worlds. I shall comment on the point whenever required.

(4) Even if we should have settled what possibilities are we still do not know well what it means for a subject to be characterized by a belief set, i.e., to exclude possibilities outside this set. Since we do not want to change the topic by revising concepts, but intend to grasp the ordinary notion of belief, it seems wise to look at how we talk about belief. This, however, gets us into another linguistic entanglement, the delicate distinction between belief and belief ascription.

\footnotetext{
${ }^{5}$ Thus, I do not agree with Lewis (1986a, pp. 145-148), insofar as he tendentiously subsumes the Wittgensteinian manner under linguistic ersatzism via what he calls Lagadonian languages.
} 
For instance, it is our common practice to ascribe de re beliefs. My thesis may indeed have raised the suspicion that its motivation lies in that phenomenon. Quite to the contrary, though. The thesis has nothing to do with de re beliefs or belief in singular propositions. This could have been clear from my reference to doxastic alternatives and belief sets, since already Quine (1956) told us with his Ortcutt story that de re contents believed are almost inevitably contradictory and thus defy direct treatment in terms of the exclusion of possibilities. They can be related to doxastic alternatives and belief sets only indirectly by such maneuvers as have been proposed by Kaplan (1969) and Lewis (1979, sect. XIII).

(5) The point runs deeper. Kripke (1972), Putnam (1975), and Burge (1979) have shown us that our de dicto belief ascriptions are de re in a way, too, either because there are many rigid designators, proper names and natural kind terms at least, for which de dicto coincides with de re, or because de dicto ascriptions implicitly contain a de re reference to communal linguistic practices (not necessarily known to the ascribee). Hence, Quine's point and its consequences generalize to de dicto belief ascriptions; this, I take it, is the upshot of Burge (1979) as well as Kripke (1979).

Burge (1979) has expressed the issue in a different way. He arrived at the antiindividualistic conclusion that believing that $p$ is (usually) not an internal state of mind; it is a psychological state in the wide, not in the narrow sense, to use Putnam's (1975) terms. There may be mental states conforming to methodological solipsism, but the propositional attitudes so central to our psychology do not belong to them. Or in still other words: there are no narrow, only wide contents. By contrast, we must note that by hoping to represent beliefs and their contents in terms of doxastic alternatives we have already put our stakes on individualism. Contents thus characterized must be narrow contents. The reason is basically the Quinean one: the wide contents believed may easily be, and often are, contradictory, and hence they are not suited for representation in terms of doxastic alterntives.

How are we to deal with this conflict? We might confine attention to restricted scenarios in which the difference between narrow and wide contents does not arise. This is probably the normal unreflective attitude towards these problems, though none we can maintain as philosophers. We might argue about the arthritis example of Burge (1979), the water example of Putnam (1975), and their variations. But I am not inclined to do so; I find them entirely plausible. We might start 
a philosophical argument about individualism. Then I had to write a different paper; so let me simply confess my individualism. Many think, of course, that this issue dooms the whole approach of understanding contents as sets of doxastic possibilities. But this would deprive my paper of its presupposition.

We should do none of this. We should rather draw the internalistic conclusion that a further disentanglement is required. There is no way of directly understanding doxastic alternatives and belief sets in terms of ordinary talk about belief. The relation between the basic internalistic characterization of belief in terms of doxastic alternatives and the common practice of de dicto and de re belief ascriptions can and must rather be construed in some indirect way. How exactly is, however, not our present task, all the more so as de dicto and de re ascriptions are not neatly separated, but thoroughly intermixed in a way hard to cope with for the semanticists of belief sentences. ${ }^{6}$

(6) However, this conclusion still leaves with the task of offering some positive characterization of doxastic alternatives and belief sets, i.e., with the question: what does it mean for a subject to exclude a doxastic possibility? Again we must avoid linguistic answers. If possibilities were state descriptions, they could be excluded by denying them; but they aren't. Similarly, the method so dear to Quine of asking subjects for assent or dissent at best elicits de dicto beliefs. But we want to know about the exclusion of whole possible worlds and not of partial linguistic representations of them.

Indeed, I find the literature surprisingly silent on this question. Even Lewis (1986a, sect. 1.4, in particular pp. 35ff.) avoids a direct answer and prefers a functional characterization: the belief set and thus the beliefs of a subject (or her more finely gradated attitudes) are those that best systematize her behavior. Yes, certainly. The same spirit is found in the proposal of Beckermann (1996) to consider belief, as it were, as a magnitude taking propositions as values (just as length is a magnitude taking positive real numbers as values) and to devise a measurement theory for this magnitude by behavioral laws. Is there no more direct answer?

There is, and it is suggested by all these twin stories initiated by Putnam (1975) that invariably depend on substantially different possibilities that are nevertheless indistinguishable for the subject. As is more extensively argued in Haas-Spohn,

\footnotetext{
${ }^{6}$ See, e.g., Schlenker (1999) and Maier (2006). For a good survey see also MacKay, Nelson (2005).
} 
Spohn (2001, sect. 2 and 3) the distinguishability referred to is not a superficial one using only fast or sloppy, e.g., purely sensory methods, but the maximally thorough-going one using all our receptive, experimental, and judgmental powers to an ideal degree. That is, what is suggested is the following criterion (that one might call operational if it were not so excessively hypothetical):

Take a certain belief state of a subject. Suppose we somehow deep-freeze this state so that nothing is lost or added. Now confront the subject with a doxastic possibility, i.e., an entire possible world. In this world she is allowed to investigate everything everywhere. She may inspect all molecules under all kinds of microscopes, she may learn every language, take every perspective, etc. If there is anything in this world that the subject would not have expected according to her frozen belief state, then this world is excluded according to it and not a doxastic alternative. In other words: If the belief state the subject would get into through such a complete inquiry is merely an expansion of her frozen state and not a revision, then this world is a doxastic alternative, i.e., a member of her belief set.

For instance, on the basis of such a full investigation Putnam's Oscar at 1750 could, of course, distinguish $\mathrm{H}_{2} \mathrm{O}$ from XYZ and Earth from Twin Earth, but they are not distinguished in his beliefs; if one is part of his doxastic alternatives, the other, is, too. Likewise for Burge's Fritz vis à vis worlds where "arthritis" means arthritis and worlds where "arthritis" means "tharthritis". This is the intended result.

This explanation makes sense only if possible worlds are understood as Lewisian ones. In her investigation the subject must grapple with the worlds, and hence they must be concrete objects to be grappled with. States of affairs or Wittgensteinian worlds cannot be inquired in this way, they can just be assumed or acknowledged. However, I do not want to press this point. The main argument of this paper should be independent of it.

Of course, this characterization of belief sets is not only unduly hypothetical, but also unduly idealized. Even if we ignore the entirely fictional character of this criterion, the test subject would often be unable to clearly say yes or no. She would often be unsure or indeterminate about many things. She will have only degrees of belief. The way and the order she would be presented with the possibilities would influence her response. And so on. However, as far as I see, such points have no force in the present context. We are not after experimental methodology. That would be a different task: to inquire the extent to which actually 
feasible discrimination tests could approximate this vastly counterfactual criterion.

Two things should be emphasized concerning this explanation of belief sets. It is, first, individualistic, as we said is required. Our criterion elicits the totality of the subject's cognitive life as his intrinsic disposition; it presupposes or holds fixed nothing external to the subject, and the elicited belief set can change only by changing the subject and not by merely changing his environment. Secondly, the criterion is sufficiently detached from language. Languages enter the picture only as parts of possible worlds; of course, no world could be a doxastic alternative if it did not contain a language and language users familiar to the subject.

Indeed, belief sets will be virtually indescribable. This is no surprise. Of course, our discriminatory capacities by far outrun our linguistic expressiveness. They even outrun the descriptive power of the most ingenious psychologists whence our useful and well established practice of only somehow approximating belief sets by our de dicto and de re ascriptions. For instance, we have an extremely good capacity to recognize objects in every-day life and it would be even better in our counterfactual test. However, it is rarely perfect, we rarely know the essence of an object in order to infallibly identify it. Our recognitional capacity is so to speak non-rigid, and it is hard to say by which (relational) features it is guided. Still, because it works so well it is a small mistake to describe it with a rigid name for the subject recognized. All this is not to say, though, that belief sets are indescribable in principle. There is no reason why they should be. They are only so incredibly hard to describe. ${ }^{7}$

So far I have only explained how the propositional conception of contents is to be properly understood, by disentangling it from language in five ways: by distinguishing it from syntactic conceptions of the objects of belief, by reducing various semantic conceptions of contents to a neutral common core in terms of sets of possibilities, by assuming a non-linguistic characterization of these possibilities, by decoupling the basic conception of belief from our practice of belief ascriptions, and finally by giving also a non-linguistic characterization of what it means to exclude a possibility. Thereby the stage is set for the issue to be discussed in the paper, since the intentional conception to be argued for is nothing but a refinement of the propositional conception.

\footnotetext{
${ }^{7}$ Cf. also the extensive discussion under the title "disjunction problem", e.g., Fodor (1990, ch. 34), which deals with the same issue.
} 


\section{The Dialectical Background of the Thesis}

Well, the common stage is set; our preparations need still more fine-tuning. My thesis has a familiar ring and it clearly originated from thinking about the familiar literature. However, it is by no means easy to discern similar from identical theses. Therefore we should look a bit more closely at the difference between the propositional and the intentional conception of contents and its dialectical battleground. In a way, this will result in a final subtle step of disentangling epistemology from semantics.

One similar thesis is the thesis about the indispensability and irreducibility of de se and de nunc attitudes, a deep point first advanced by Castañeda (1966) and powerfully reinforced by Perry (1979) and Lewis (1979). I mentioned already in section 1 that possible worlds $w$ won't do as doxastic possibilities; they have to be at least centered worlds $\langle w, s, t\rangle{ }^{8}$ Of course, the above criterion for doxastic alternatives has to be modified accordingly: the subject's full investigation need not only check whether the world $w$ as such conforms to her beliefs, but also whether the possible object $s$ might be she herself and whether the possible time $t$ might be her present time in $w$ according to her beliefs.

The point seems generally accepted, and I accept it, too. But there is reason for modesty. There was an argument between Lewis (1979) and Stalnaker (1981) in which Stalnaker defended the narrow propositional conception according to which possible worlds are good enough as doxastic possibilities even in view of the examples apparently favoring Lewis' position, the most extreme one being the one of Jahwe and Zeus (cf. Lewis 1979, sect. V). Lewis' position is certainly more intuitive and elegant. This is confirmed by Haas-Spohn (1995, sect. 2.2). However, she makes clear that it is no more than that; ultimately, Stalnaker has an equivalent way of representing matters.

It may seem that the intentional refinement of the propositional conception is of the same kind as the de selde nunc refinement and supported by the same kind of argument. I think this would be a misperception. Egocentricity or self-

\footnotetext{
${ }^{8}$ Lewis (1979) is able to further reduce centered worlds to properties, but only because he, contestedly, assumes first that each individual inhabits only one possible world and secondly that persons or subjects are (mereologically) composed of momentary person stages. I shall ignore this reduction in the sequel.
} 
consciousness and object-directedness are two different phenomena, even though Kant (1781/87, B274-279), in his refutation of idealism, has suggested a deep connection that is on the philosophical agenda since. And they require a different treatment. In any case, here I shall take the de se/de nunc refinement simply as tacitly understood. My arguments for the intentional refinement will differ from Perry's and Lewis' arguments for de se beliefs. Indeed, the case may be reversed. The argument for the intentional refinement may be adapted for $d e$ se beliefs, and thus the case against Stalnaker (1981) may be strengthened, though perhaps not decided.

The main source for similar theses, though, is two-dimensional semantics. The relation of my thesis to this most promising development in semantics is highly instructive, but not obvious. Let me explain it in a bit more detail. However, since I want to steer to the point relevant for this paper as directly as possible, I have to neglect a lot of interpretational variation and uncertainty in two-dimensional semantics.

The first full elaboration of two-dimensional semantics was Kaplan (1977). ${ }^{9}$ His goal was to deal with the semantics of indexicals, demonstratives, and possibly other context-dependent expressions. For this purpose, the interpretation function to be recursively explained for a language must assign characters to expressions; the character $\|\alpha\|$ of $\alpha$ assigns an extension to $\alpha$ relative to a context of utterance and a circumstance of evaluation in Kaplan's terms, or relative to a context $c$ and an index $i$, as I shall say following Lewis (1980). Thus, $\|\alpha\|(c)(i)$ is the extension of $\alpha$ at $c$ and $i$, and $\|\alpha\|(c)$ is the intension of $\alpha$ in the context $c-$ or the secondary intension of Chalmers (1996, sect. 2.4) or the $C$-intension of Jackson (1998, ch. 2). In this way Carnap's framework of intensions and extensions is preserved by Kaplan.

Now an important issue is the structure of contexts $c$ and indices $i$. Contexts $c$ must collect those contextual features on which the intension of $\alpha$ as used in $c$ may depend. Indices $i$ must be so structured as to get the semantic recursion running. Which parameters of contexts and indices need to be assumed is a ramified and continuing discussion. It is strongly suggested, though, that we need the following index parameters in $i$ : a world $w_{i}$ for treating modality, a time $t_{i}$ in order to deal with tenses and temporal quantifiers, and a variable assignment or a sequence

\footnotetext{
${ }^{9}$ It was, though, a larger group at the Philosophy Department of UCLA that predominantly developed the theoretical field since the late 60's.
} 
$\mathbf{d}_{i}$ of objects in order to treat objectual quantifiers. The latter point is already Tarski's deep insight that it is not truth, but satisfaction that can be recursively defined for first-order languages. Moreover, it is strongly suggested that we need the following context parameters in $c$ : a context world $w_{c}$ since we are able to contextually refer to practically every feature of the world, a speaker $s_{c}$ and an utterance time $t_{c}$ for localizing potential utterances in $w_{c}$, i.e., for interpreting "I" and "now", and again a sequence $\mathbf{d}_{c}$ of objects for interpreting demonstratives. The latter point is contested, though. Montague (1974, ch. 3 and 4) explicitly chooses the latter option, although he still struggles with disentangling the roles of contexts and indices within his points of reference. Kaplan (1977, sect. XV) prefers to take what he calls demonstrations as parts of contexts instead of demonstrated objects. In (1989, pp. 582-584) Kaplan has changed his opinion and adopts a view that I would capture by enriching a context $c$ by a sequence $\mathbf{d}_{c}$ of objects as interpreted below. This is also the conclusion of Haas-Spohn (1995, sect. 4.7). The topic is an intricate one, and there is no point in starting a discussion here. I listed here what I called strong suggestions only in order to relate them to my topic, as I am about to do.

The lists of context and index parameters may seem a bit arbitrary; each follows its own apparent needs. ${ }^{10}$ Theoretical pressure is produced by the notion of utterance truth. A sentence is true in a context and at an index. An utterance is a sentence in a context, and it is true if and only if the sentence is true in that context and at the very same context taken as an index. The latter step is called diagonalization. Thus, utterance truth conditions are generated by diagonalizing the characters of the sentences uttered. Kaplan (1977, p. 547) explicitly introduces this notion in order to explain validity or logical truth for his logic of demonstratives: a sentence is logically (or a priori) true iff its utterance is true in all contexts. This is, he says on pp. 538f., how much he can capture of apriority by his logic of demonstratives.

This produces theoretical pressure because it constrains our lists of context and index parameters. Whenever we assume an index parameter, we also need a corresponding context parameter; otherwise, diagonalization is not defined. The converse need not hold. There may be more context than index parameters. For in-

\footnotetext{
${ }^{10}$ We then find also surprising proposals such as that of Lewis (1980, sect. 3 and 5) to include standards of precision among the context and possibly also among the index parameters.
} 
stance, we clearly require the contextual subject $s_{c}$, the speaker; but the evidence that we also require a subject $s_{i}$ in the index has remained unclear. ${ }^{11}$

There are two ways how we can deal with this theoretical pressure. Either, we can take it as well founded and thus as an argument for postulating an appropriate context parameter whenever we have found reason for assuming a given index parameter. Or we can treat diagonalization as a hypothesis in need of confirmation and getting confirmed when we list context and index parameters according to their independent needs and find them admitting diagonalization. Of course, these two ways are not so clearly separated. Either way, the theoretical pressure advances theoretical coherence.

Much stronger theoretical pressure is produced by what is called the epistemological reinterpretation of Kaplan's character theory initiated by Stalnaker (1978). Many think that the formal similarity between Kaplan's and Stalnaker's work is superficial and in fact utterly misleading. I don't think so. Haas-Spohn (1995, sect. 2.1, 3.9, and 4.4) gives a convincing account of how to understand Stalnaker's propositional concepts as a continuation of Kaplan's characters and how thus to explain the existing differences. I am obviously touching here a long and deep discussion that we cannot pursue here. ${ }^{12}$ Putting all niceties aside, let me bluntly state what I take to be the gist of the epistemological reinterpretation: It is that possible contexts at the same time serve as doxastic possibilities; both have the same structure. Altogether we have a very powerful constraint:

The Congruence Principle: Each index parameter is a context parameter, and the context parameters are exactly those characterizing doxastic possibilities.

For instance, when we assume contexts to be characterized as triples $\left\langle w_{c}, s_{c}, t_{c}\right\rangle$ and account for de se and de nunc attitudes by taking centered worlds $\langle w, s, t\rangle$ as doxastic possibilities, we accurately conform to this principle.

If we accept the principle, the distinction of Chalmers (2006) between a contextual and an epistemic understanding of two-dimensional semantics would collapse. The utterance truth condition of a sentence is at the same time the narrow

\footnotetext{
${ }^{11}$ See, however, Schlenker (1999, ch. 3) for a strong case in favor of this requirement.

${ }^{12}$ The most careful discussion of this issue, i.e., of a contextual versus an epistemic understanding of the first dimension of two-dimensional semantics, is found in Chalmers (2006).
} 
content associated by a subject with that sentence. Thus, in this reinterpretation diagonalization acquires great epistemological importance; and utterance truth conditions are rather called diagonal intensions or primary intensions (Chalmers 1996, sect. 2.4) or A-intensions (Jackson 1998, ch. 2). All in all we are tempted by a beautiful offer: horizontals are for metaphysics, diagonals are for epistemology, and two-dimensional semantics unites both in one framework. Perhaps too beautiful to be true.

Anyway, it should be clear by now why I was telling all this. The theoretical framework I have sketched provides great argumentative resources in relation to the thesis I want to defend. For instance, if Tarski is right about indices and the Congruence Principle is true, doxastic possibilities must contain sequences of objects. Or a bit closer to the point: given the Congruence Principle, arguments about how to deal with demonstratives automatically turn into arguments about the thesis.

This is why I said that the thesis is so hard to discern from similar ones. The arguments we usually find in the literature are semantic ones. If the Congruence Principle is presupposed in these arguments, they may be taken to support my thesis; if not, they argue for something slightly different. What is actually going on is often not so clear, however.

To be a bit more specific: Kamp (1981) has initiated the so-called discourse representation theory that has acquired great linguistic significance in the meantime (cf. Kamp, Reyle 1993). Kamp (1981, p. 282) says that he intends his account to "bear on the nature of mental representation and the structure of thought". So, all the model building in the discourse representation structures (DRS's) is to represent what is internally going on in the mind of the speaker/hearer, i.e., epistemic meanings or the diagonals in the two-dimensional picture. A crucial role in the DRS's is played by the so-called discourse referents or parameters, and those appearing in the so-called principal discourse representation may be identified, I think, with the places of the sequence of objects being part of doxastic possibilities according to my thesis. However, this identification would have to be argued, and the indispensability of discourse referents as such is rather a semantic issue. The same remarks apply to the very similar so-called file change semantics developed by Heim (1982). She clearly intends files to be states of information, i.e., as something of an epistemic nature. Again, though, her goal is to 
promote semantics, and she puts forward exclusively semantic arguments. All this does not automatically determine its relation to pure epistemology. ${ }^{13}$

Therefore I would like to state expressly that I want to uncouple my thesis from the Congruence Principle and all the two-dimensional theorizing. My intention is to entirely stay on the epistemological side and to argue for the thesis in a purely epistemological way. Of course, the two-dimensional picture is always in the background. To a good extent it is this background in which the thesis unfolds its significance, and the perspective that the thesis may provide confirmation for the Congruence Principle and thus connect up with the above-mentioned semantic developments is exciting. However, all this is to be background, not part of my thesis and my argument. I leave it to the reader to judge whether I shall have succeeded in my intention.

\section{Two Arguments for the Thesis and an Objection}

Let me resume our focal thesis: According to the intentional conception of contents a subject's belief system has addresses or file cards or discourse parameters for objects. When the subject encounters, perceptually or linguistically mediated, an object she takes interest in she creates a new address or file card. All subsequent information she takes to be about the same object will then be stored at this address. Of course, since she may misidentify objects she may store information at the wrong address, and since she may not recognize an object she may have two addresses for the same object. We must always reckon with this ontological-epistemological backlash. Doxastic possibilities also allow for relational and for general information not stored at specific addresses. Thus, the formal model in terms of doxastic possibilities is broader than the vivid picture of a file suggests. In fact, Heim (1982, p. 287) defines a file precisely as a set of doxastic possibilities in the intentional sense.

This description also indicates how my quasi-operational criterion for the exclusion of doxastic possibilities is to be modified for the intentional conception: The quadruple $\langle w, s, t, \mathbf{d}\rangle$ is a doxastic alternative of a subject at a certain time if

\footnotetext{
${ }^{13}$ The notion of a discourse referent seems to go back to Karttunen (1969). He also uses the picture of a file. However, it was only Kamp (1981) and Heim (1982) who crucially advanced the long semantic struggle with pronouns and definite and indefinite noun phrases.
} 
and only if she would admit after the most scrupulous investigation of $w$ and all objects in $w$ from all perspectives available in $w$ that $s$ conforms to her self-image, $t$ to her image of the present time, the objects $d_{1}, d_{2}, \ldots$ in $\mathbf{d}$ to the images stored at her addresses $1,2, \ldots$, and $w$ to her picture of world, that is, if the doxastic state she would arrive at after that investigation of $\langle w, s, t, \mathbf{d}\rangle$ would be an expansion and not a revision of her present state. ${ }^{14}$

How, then, may we argue for the thesis? To begin with, it is noticeable that there seem to be no arguments for related theses confined to static scenarios, to the beliefs of a single person at a single time. This may have the following reason: Suppose we understand belief contents in the intentional way, i.e., as satisfaction conditions of open formulae (if we could linguistically represent the contents). This allows an easy derivation of belief contents in the propositional sense, i.e. truth conditions. Logicians usually associate open formulae with universal closures; but this is obviously inappropriate in our case. To believe a satisfaction condition rather means to believe that there exist objects corresponding to the information stored at the various addresses, and this amounts to the existential closure of the satisfaction condition. Now, it seems plausible and arguable that a static theory of belief would be concerned only with truth conditions and cannot by itself discriminate different satisfaction conditions having the same truth condition. However, I am not aware that that argument has actually been carried through.

In any case, all the existing arguments in the vicinity of the intentional conception refer to dynamic scenarios in some way or other. This is even true of the arguments for the irreducibility of beliefs de se and de nunc. However, I do not see how to transfer these arguments to our case. As already indicated, discourse representation theory and file change semantics are rather occupied with finding adequate semantic representations of texts and discourses as they evolve. So, again I do not see how to turn their arguments about anaphoric reference and related phenomena into an argument about pure epistemology. Only Perry (1980) directly addresses belief and its change or preservation and discusses various dynamic examples showing the need for what he calls a file. Let me adapt his kind of examples to my somewhat different framework; I shall explain our differences afterwards.

\footnotetext{
${ }^{14}$ The numbering of the addresses is inessential. What matters is the assignment of the possible objects in a doxastic possibility to the somehow well distinguished addresses of the belief state.
} 
Typically, changes in beliefs are driven by perception, and typically we use indexical descriptions for perceived objects. The girl about ten meters left of me just hurt her knee by falling from her skateboard - this is what I just saw and what I came to believe. There are two ways to describe the increment of my beliefs: according to the propositional conception my old belief set is conjoined with the truth condition of the sentence "The girl about ten meters to the left of me just hurt her knee". (Let us ignore that the content of my perception obviously exceeds the content of this sentence.) According to the intentional conception my prior doxastic state is enriched by adding a new address and there storing the information "is a girl, is about ten meters left of me, just hurt her knee". So far both descriptions seem equally acceptable.

The story continues, however. I realize that I know the girl; she is my neighbor's daughter. I shall soon have forgotten the indexical description; perhaps there were several girls around, and it is just too tedious to memorize where all of them were placed. So, the other day all I remember is that my neighbor's daughter hurt her knee. However, since I still rely on a description of the girl the situation did not really change. The only difference to the first case is that according to the intentional conception the new information will be stored at an old address, namely the address that already contains the information "daughter of my neighbor". So, again, there is no reason to prefer one description to the other.

However, you will not be surprised to read that the full story goes like this: My neighbor actually has two daughters who are identical twins. Despite numerous encounters I am still unable to tell them apart. In this case it is plausible to maintain that I have exactly the same information about both girls. Let us summarize this information by the rather complex concept $F$. So, according to the propositional conception my prior doxastic state before the incident (as far as these girls are concerned) may be characterized by the following proposition:

$$
\{w|w|=\vee x \vee y(x \neq y \wedge F x \wedge F y)\}
$$

According to the intentional conception this state is best captured by an open formula, i.e. by the following content:

$$
\{\langle w, x, y\rangle|\langle w, x, y\rangle|=x \neq y \wedge F x \wedge F y\}
$$


(where the sequence $\mathbf{d}$ of objects is reduced to the pair $\langle x, y\rangle$ that only matters). Now I said I remember from the incident I observed that one of the girls hurt her knee, i.e., for short, that she has property $G$. According to the propositional conception my posterior doxastic state some time after the incident is represented thus:

$$
\{w|w|=\vee x \vee y(x \neq y \wedge F x \wedge F y \wedge G x)\}
$$

According to the intentional conception the new state is represented by one of the following sets:

(I2b) $\quad\{\langle w, x, y\rangle|\langle w, x, y\rangle|=x \neq y \wedge F x \wedge F y \wedge G y\}$, or

(I2c) $\{\langle w, x, y\rangle|\langle w, x, y\rangle|=x \neq y \wedge F x \wedge F y \wedge(G x \vee G y)\}$.

(I2a) and (I2b) apply if, for whatever reason, I come to store the information at a specific address. (I2c) applies if I have no idea which of the two girls was injured. As I have told the story so far, the latter case will seem to be the more plausible, indeed the only possible one. However, I hope to make clear below that the former cases may not be disregarded.

This scenario constitutes the setting of my first argument. How should we describe the increment in belief? According to the intentional conception the increment (I1/2) may be simply conjoined. That is, in the three variants the increments are:

(I1/2a) $\{\langle w, x, y\rangle|\langle w, x, y\rangle|=G x\}$, or

(I1/2b) $\{\langle w, x, y\rangle|\langle w, x, y\rangle|=G y\}$, or

$(\mathrm{I} 1 / 2 \mathrm{c}) \quad\{\langle w, x, y\rangle|\langle w, x, y\rangle|=G x \vee G y\}$.

And in each variant we just have (I1) $\cap(\mathrm{I} 1 / 2 \mathrm{a}, \mathrm{b}, \mathrm{c})=(\mathrm{I} 2 \mathrm{a}, \mathrm{b}, \mathrm{c})$.

The case is not so simple, however, with the propositional conception. The introductory versions of the story still allowed the conjunctive addition of:

$\left(\mathrm{P} 1 / 2^{\prime}\right) \quad\{w|w|=G(1 x F x)\}$. 
The last problematic version, though, was so constructed that this idea is blocked, because I do not know any identifying description of the girls and thus the description $x F x$ does not refer according to my beliefs. What to do? Logically speaking, the whole posterior doxastic state

$\left(\mathrm{P} 1 / 2^{\prime \prime}\right) \quad\{w|w|=\vee x \vee y(x \neq y \wedge F x \wedge F y \wedge G x)\}$

may be taken as the increment in belief; but intuitively the increment is not that big. The other extreme is to take the material implication

$\left(\mathrm{P} 1 / 2^{\prime \prime \prime}\right)\{w|w|=\vee x \vee y(x \neq y \wedge F x \wedge F y) \rightarrow \vee x \vee y(x \neq y \wedge F x \wedge F y \wedge G x)\}$

as increment; but we thereby ascribe a surprisingly complex logical form to a rather simple information. One might also try something in between these extremes, for which, however, no simple logical form is in sight, either. So, here is the first argument: In the example the informational increment intuitively appears to be a simple conjunctive addition but the increment cannot be captured as such within the propositional conception, in contrast to the intentional conception which is able to do so. ${ }^{15}$

The argument is certainly not conclusive. Christoph Lumer pointed out to me (personal communication) that one could easily introduce a definite description for a pair of individuals ("the twins of my neighbor") and that the propositional conception could adequately represent the increment by using that definite description ("one of the twins of my neighbor hurt her knee"). A different point: Ede Zimmermann mentioned to me (personal communication) that propositions, being sets of worlds, have no logical form and that the argument therefore makes no sense, strictly speaking. Nevertheless, the argument certainly points to a difficulty.

The second argument refers to the same scenario. It starts from an observation already made, namely that the intentional conception allows for three different increments (I1/2) in information from (I1) to (I2). These increments result in three different belief states. However, their existential closures are logically equivalent; it does not make a logical difference whether $G x$ or $G y$ or $G x \vee G y$ is added as a

\footnotetext{
${ }^{15}$ Similarly, Heim (1982, p. 305) assumes that the file change brought about by continuing a text with an atomic formula just consists in conjoining the satisfaction condition of that formula to the prior file. This inspired me to the above argument.
} 
conjunct within the scope of the existential quantifiers $\vee x \vee y$. So, according to the propositional conception there is a unique posterior belief state. What is intuitively more adequate: a unique increase or the unfolding into three possibilities? I would like to shift our intuitions to the latter.

For this purpose, let me introduce a second piece of information about one of the girls consisting in the predicate $H$. I do not think of another observation. This would not bring substantial news because the intentional conception would again allow three ways to account for the new piece of information and the propositional conception would do so as well, since the first piece of information about the injured knee already destroyed the symmetry of the bound variables. I am rather thinking of a case in which I suddenly remember, say, that one of the twins has a liver spot under her left eye and that this mark in principle allowed me to distinguish them, even though I mostly confused them, not thinking of the distinguishing mark.

So, suppose $H$ is the concept of having a liver spot under her left eye and that, within the intentional conception, the free variable $x$ represents the address for the girl with the liver spot. This conception allowed three ways for accounting for the perception about the injured knee. Because of my recollection we now have to add the conjunct $H x$ in each case. So, there are again three possibilities to account for the resulting doxastic state:

(I3b) $\quad\{\langle w, x, y\rangle|\langle w, x, y\rangle|=x \neq y \wedge F x \wedge F y \wedge G y \wedge H x\}$, or

(I3c) $\quad\{\langle w, x, y\rangle|\langle w, x, y\rangle|=x \neq y \wedge F x \wedge F y \wedge(G x \vee G y) \wedge H x\}$.

As stated, though, the increment is the same in all three cases:

$$
\{\langle w, x, y\rangle|\langle w, x, y\rangle|=H x\}
$$

And again, we have $(\mathrm{I} 2 \mathrm{a}, \mathrm{b}, \mathrm{c}) \cap(\mathrm{I} 2 / 3)=(\mathrm{I} 3 \mathrm{a}, \mathrm{b}, \mathrm{c})$, respectively.

Note the important fact that this continuation of the story also supports my claim above that there are three ways to account for the first increase in information. At first blush it seemed that I could only add the information $G x \vee G y$ because I did not have any clue which of the twins injured her knee. However, a mark like the liver spot might cause me to store the information at a specific ad- 
dress even if I am not aware of the mark and could not tell afterwards why I did so.

The propositional conception leads to a different treatment of my recollection. According to this conception there are three possible final doxastic states:

(P3a) $\quad\{w|w|=\vee x \vee y(x \neq y \wedge F x \wedge F y \wedge G x \wedge H x)\}$, or

(P3b) $\quad\{w|w|=\vee x \vee y(x \neq y \wedge F x \wedge F y \wedge G x \wedge H y)\}$, or

$(\mathrm{P} 3 \mathrm{c}) \quad\{w|w|=\vee x \vee y(x \neq y \wedge F x \wedge F y \wedge G x \wedge(H x \vee H y))\}$,

where $(\mathrm{P} 3 \mathrm{c})$ is logically equivalent to

(P3d) $\quad\{w|w|=\vee x \vee y(x \neq y \wedge F x \wedge F y \wedge(G x \vee G y) \wedge H x)\}$

Which variant applies depends on whether the recollection concerns the girl with the injured knee, as in (P3a); the other girl, as in (P3b); or none of them specifically, as in (P3c). The increments thus are:

$(\mathrm{P} 2 / 3 \mathrm{a}, \mathrm{b}, \mathrm{c})=(\mathrm{P} 3 \mathrm{a}, \mathrm{b}, \mathrm{c})-(\mathrm{P} 2)$, respectively,

which are three different increments. Hence, what seemed to be one specific recollection is here split into three possible recollections. One might suggest that the order of changes in my doxastic states should be reversed, i.e., that the recollection has to come first and that the observation joins; in this case the recollection would bring about a unique change and the observation would result in three possible changes. This would then correspond to what you get according to the intentional conception. Indeed, past observations are sometimes reinterpreted in the light of emerging recollections. However, this is not always the case, and in my version of the story it did not play a role.

So, this is the second argument: According to the propositional conception the observation leads to a unique change of my doxastic state and the recollection may then take three different forms. Intuitively, however, it is just the other way round, and so it is represented by the intentional conception. Hence, the propositional conception gives an incorrect account of the succession of observation and recollection and can render it correct only by artificially reversing the real succession of events. 
I mentioned already that these arguments are basically of the same kind as those of Perry (1980). A minor difference is that he worries about preservation or the continuity of belief, whereas I argue with the adequate representation of belief expansion. The major difference is that he is not operating with the internalistic conception of narrow contents characterized by the exclusion of possibilities. He rather considers whether the continuity of belief consists in the preservation of the situation believed (in his technical sense) or in the retention of text by which the belief can be expressed at the various times, and he finds convincing examples against both proposals as well as against various combinations of them, thus motivating the introduction of the new theoretical concept of a file, as he says on $\mathrm{p}$. 328. However, situations in Perry's sense are wide contents, and the criterion of retention of text again involves us in issues of linguistic meaning, whereas I wanted to dissociate myself from both these notions. This is why it is difficult to compare our frameworks and to decide whether or not our arguments come exactly to the same.

However, the gist of the arguments is always the same. It is about the availability of names or definite descriptions or equivalent devices. That is why I chose the twin story. Similarly, Perry emphasizes again and again that he cannot find them in his examples that, by the way, also use such ingredients as confusion and failing memory. This is also the point of the arguments in the linguistic cases that doubt, for instance, the adequacy of the proposal of Evans (1980) to treat certain occurrences of anaphoric pronouns as E-type, i.e., as definite descriptions; cf. the critical discussion of Heim (1982, sect. I.1.4 and I.2.3).

Zimmermann (1999, pp. 359ff.), objects. He wants to defend the availability of definite descriptions and thinks that I have misrepresented the example. When I see the girl falling from her skateboard, I do not only see that she has $G$, i.e., that she has hurt her knee; rather I see her instantiating an enormously complex property $G^{*}$ (most of which may escape my descriptive capacities). So, my perception actually moves me into the doxastic state (as far as the example is concerned):

$(\mathrm{P} 2 *) \quad\left\{w|w|=\vee x \vee y\left(x \neq y \wedge F x \wedge F y \wedge G^{*} x\right)\right\}$

Of course, (P2*) entails (P2), since $G^{*}$ entails $G$.

Moreover, Zimmermann says, and I agree, that in that situation there must have been some perceivable property $R$ of the girl because of which I recognize her to 
be one of my neighbor's daughters of whom I believe the whole of $F$. Clearly, $R$ must be part of $G^{*}$. So, in that situation I have also the background belief:

$$
\left\{w|w|=\wedge x\left(G^{*} x \rightarrow R x\right) \wedge \wedge x(R x \leftrightarrow F x)\right\}
$$

However, on this background the increment I have learnt in moving from (P1) to $(\mathrm{P} 2 *)$ has a simple representation:

$\left(\mathrm{P} 1 / 2^{*}\right)\left\{w|w|=\vee x G^{*} x\right\}$

It is easily checked that indeed $(\mathrm{P} 2 *)=(\mathrm{P} 1) \cap(\mathrm{PB}) \cap(\mathrm{P} 1 / 2 *)$. In this way the difficulties with $(\mathrm{P} 1 / 2 \mathrm{a}, \mathrm{b}, \mathrm{c})$ disappear; there is no need to worry about them.

The difficulty with the recollection in the continuation of my story dissolves in the same way. We may well assume the recollection to have a unique content:

$(\mathrm{P} 2 / 3) \quad\{w|w|=\vee x(F x \wedge H x) \wedge \vee x(F x \wedge \neg H x)\}$

As desired, it is rather the observation taking three variants; the perceived totality $G^{*}$ may contain $H$ or $\neg H$ or neither. That is, $G^{*}$ may be such that I believe after the observation:

$\left.(\mathrm{P} 2 * \mathrm{a}) \quad\left\{w|w|=\wedge x\left(G^{*} x \rightarrow H x\right)\right\}\right\}$

(P2*b) $\left.\left\{w|w|=\wedge x\left(G^{*} x \rightarrow \neg H x\right)\right\}\right\}$

$\left.(\mathrm{P} 2 * \mathrm{c}) \quad\left\{w|w|=\vee x\left(G^{*} x \wedge H x\right)\right\} \wedge \vee x\left(G^{*} x \wedge \neg H x\right)\right\}$

So, we have $(\mathrm{P} 2 *) \cap(\mathrm{P} 2 * \mathrm{a}, \mathrm{b}, \mathrm{c}) \cap(\mathrm{P} 2 / 3) \subseteq(\mathrm{P} 3 * \mathrm{a}, \mathrm{b}, \mathrm{c})$, respectively (only " $\subseteq$ " because the $G$ in $(\mathrm{P} 3 \mathrm{a}, \mathrm{b}, \mathrm{c})$ is weaker than $\left.G^{*}\right)$. The trifurcate effect of the recollection is thus explained by the possible shapes of the observation, in no worse a way than according to the intentional conception.

Zimmermann concludes that the propositional and the intentional conception are explanatory equally successful and that hence the first is to be preferred because of its greater simplicity. 


\section{The Method of Sufficiently Fine-Grained Descriptions}

The objection is well taken, I think; there is no direct way to refute it. Mutatis mutandis, it may apply also to Perry's examples, though it need not carry over to the linguistic arguments that are different. What the objection does, then, is to shift our argument to a more strategic level, which I take to be the proper level of our dispute well-prepared by the previous section. In fact, it is a nice exemplification of what may be called the method of sufficiently fine-grained description, a method widely applied in philosophy, whereas my arguments intimated to avoid this method, though in a way not yet made explicit. Let me unfold this strategic issue in this section.

The point of the objection was to find a sufficiently rich property $G^{*}$ that entailed both the property $G$ of hurting one's knee on which I had originally focused and the property $R$ sufficient to recognize the twins. It seems easy to find that fine-grained $G^{*}$ in my every-day example, and it seems plausible that when confronted with ever more contrived examples one will succeed in the same way with even more fine-grained descriptions. By contrast, my arguments were meant to stay away from that strategy by focusing on that girl's hurting her knees as the only perceptual information remaining, by initially abstracting from the discriminating liver-spot, etc. On this coarse level of description my arguments certainly hold good.

This is a discursive pattern we often find in philosophy: Under the force of certain arguments one feels compelled to resort to more fine-grained descriptions of the cases at hand. Sometimes, one may even observe an absurd race between examples and escapes. The escapes seem to be the winning strategy, and I am happy to grant that they work (though there remain doubtful cases). However, one is so compelled only by being caught in a certain theoretical framework. And everyone would be happier, I assume, when being provided with theoretical resources freeing us from these argumentative forces and absurd races. Thus, there is a challenge to find these alternative theoretical means. I am convinced that in the end it is always possible to meet this challenge and that the alternative theories always turn out to be more satisfactory.

I have found at least four quite varied examples of this discursive pattern, and even though it may look like changing the topic, I think it is really instructive to study these examples, in their own right, but also with respect to our present case. 
The historically first example I am aware of is decision theory, i.e., the groundbreaking account of Savage (1954) and in particular its section 5.5 on small worlds the moral of which is, I think, still not fully appreciated. Savage faced a straightforward problem: In a decision situation one should take into account every item considered relevant to one's decision. Of course, one should! However, if one takes this demand seriously, one soon sees there is no end to the relevancies. The consequences and even, more narrowly, the favorable and unfavorable consequences of one's decision indefinitely extend into the future, the circumstances on which these consequences depend as well get broader and broader, and the decision at hand turns out not to be separable from all one's future decisions. Thus, Savage (1954, p. 83) ends up considering that "a person has only one decision to make in his whole life". He finds the consideration "stimulating", but also "highly unrealistic" and "unwieldy"; one might also find stronger words. His problem then "is to say as clearly as possible what constitutes a satisfactory isolated decision situation".

He solved it with his theory of small worlds. What he did there was to show how to reduce a decision model referring to fine-grained states of world, acts, and consequences to a provably equivalent decision model working with more coarsegrained states of the world, acts, and consequences; "provably equivalent" here means "to provably lead to the same decision". So, in effect, there were two problems, that of isolating independent decision situations and that of reducing grand to small decision situations, and despite his rhetoric he rather solved the second. Moreover, his solution was not perfectly general; as he was well aware, it worked only under certain restrictive assumptions. However, if one changes to the decision models of Fishburn (1964), the reduction works generally and without constraints, for me the ultimate reason to prefer Fishburn's over Savage's modeling. ${ }^{16}$

What is remarkable about this is that the postulate of equivalent reducibility of grand-world to small-world decision models is a substantial and consequential postulate. As just mentioned, one consequence concerns the precise format of decision models. Another consequence, and one that is very insufficiently appreciated as far as I see, concerns the decision rule that is required to be invariant under reductions. Savage, of course, applies the decision role of maximizing expected utility, and the natural reduction method is just the one that keeps this decision

${ }^{16}$ All this is fully explained in Spohn (1978, sect. 2.3, 3.5, and 3.6). 
rule invariant; in fact, the decision rule is nothing but the maximal reduction in which only the possible actions and nothing else is considered (cf. Spohn 1978, sect. 3.6, and also 1982, pp. 246-249). However, for other decision rules there are no good reduction methods that respect their invariance. To mention a familiar example: In a sufficiently fine-grained description each decision of mine (staying at home, turning on the radio, etc.) might have the worst possible consequence, i.e., result in getting killed. Given this fine-grained description, the maximin decision rule absurdly dictates indifference between all my options, and equivalent reduction would have to preserve this indifference. I wonder which decision rules are compatible with the postulate of equivalent reducibility and whether another justification of maximizing expected utility might be forthcoming in this way.

My second example is learning by conditionalization. For centuries, the only formal account of learning was Bayes' theorem or simple conditionalization with respect to the proposition learned. Jeffrey (1965, ch. 11), however, opened our mind by proposing his rule of generalized conditionalization, according to which what is learned is not a proposition, but some new probability distribution over some propositional partition induced by experience. The idea was to allow for the case of uncertain evidence and thus to avoid the old foundationalist presupposition that evidence is always certain. Jeffrey's rule then made a specific proposal for how to change one's subjective probabilities in the light of such uncertain evidence.

Levi (1967) started an argument with Jeffrey. He thought that Jeffrey's generalization would be superfluous and unjustified: unjustified because only certain evidence can justify the doxastic changes induced by it, and superfluous because one can always find an evidential proposition which is learned for sure and which induces the distribution representing uncertain evidence according to Jeffrey. Here it is again, our discursive pattern: Levi appeals to sufficiently fine-grained descriptions, whereas Jeffrey wants to avoid them.

We need not follow the argument about justification. Still, Levi may be right, we may always find a sufficiently detailed evidential proposition and thus represent learning by simple conditionalization. Of course, these evidential propositions soon outrun our linguistic descriptions. Often, the best we can say about our evidence is that the scene before us appeared to us in such and such a way (which is not an especially helpful proposition to conditionalize on). But even if we grant Levi's argument, the point is simply that simple conditionalization is not invariant 
under variations of descriptive granularity. Doxastic changes that can be described by simple conditionalization within a fine-grained propositional framework cannot be so described within coarsenings of that framework. By contrast, Jeffrey's generalized conditionalization is provably invariant in this way; a generalized conditionalization turns into another by coarsening the propositional framework. This is why I find Jeffrey's rule theoretically superior to Levi's insistence on traditional conditionalization. Indeed, we have here a particularly clear exemplification of our discursive pattern.

A rich field of application of the method of sufficiently fine-grained description is causation, my third illustration. There are in fact two variants, the method of fine-graining causal chains and the method of fine-graining events (i.e., causes and effects). As already observed by Salmon (1980) $)^{17}$ and many others, these are the main methods of dealing with recalcitrant examples. Let me focus here on just one problem case, the problem of (symmetric) causal overdetermination. This is indeed a problem for almost all theories of (deterministic) causation. Regularity theories tend to be too liberal; they find overdetermination where there really is none. But this may be counted against regularity theories. Conversely, counterfactual analyses tend to be too restrictive, to allow no overdetermination whatsoever. Hence it has become popular to explain away overdetermination: if we describe the allegedly overdetermined effect in a sufficiently detailed way, we see that it would not have realized in exactly this way, if one of the allegedly overdetermining causes had not occurred. Thus these causes turn out to be joint contributory causes; that is the normal way of causation. Again, one can consider more and more contrived examples. Perhaps the strategy of sufficiently finegraining the effects always succeeds. ${ }^{18}$

However, the counterfactual analysts pursue this strategy not because it would be so natural, but because they are captives of their theoretical framework that seems to leave them no other choice in dealing with overdetermination. Change the framework, and the dialectics of the case is completely changed. At least this is what I have proposed since Spohn (1983). I prefer to analyze causation in terms of ranking functions instead of counterfactual conditionals; for a recent attempt to

\footnotetext{
${ }^{17} \mathrm{He}$ speaks of "the method of more detailed specification of events" and "the method of interpolated causal links".

${ }^{18}$ For all this cf. Lewis (1986b, pp. 207-212). Interestingly, Lewis is not always in favor of applying the method of fine-grained descriptions. In (2000, pp.183f.) he explicitly refuses to fine-grain causal chains in order to reduce so-called cases of preemption by trumping to cases of preemption by cutting.
} 
defend my analysis see Spohn (2006). Section 5 there explains how this analysis can allow for overdetermination in a straightforward and appropriate way. It is not committed to artificially shifting or expanding the description of the problem cases.

The issue is certainly more complex than just displayed. However, there is no point in attempting to develop the complexities here; see Spohn (2006). Still, the sketch I have given seems basically fair. We again have the choice between one theory being forced to invoke fine-grained descriptions and another theory not being so forced. And again I have no doubt that the latter is more fruitful even if the former remains defensible.

My last example is closest to our concerns; it is the debate between Lewis and Stalnaker about the representation of de se beliefs. As mentioned in section 3, Lewis (1979) accounted for de se beliefs by taking centered worlds as doxastic possibilities, and Stalnaker (1981) argued that worlds would do. Again, the debate was about fine-graining. Lewis suggested coarse-graining by assuming poor Lingens to have completely forgotten who he is, and Stalnaker enforced finegraining by pointing out that Lingens' perceptual perspective would still be detailed enough to ensure self-identification. Lewis then introduced his ultimate, desperate example of the two gods propositionally omniscient, but not knowing who they are. It is hard to figure out the details of the case. Somehow, divine knowledge must be very different from human knowledge; and so the force of that example remains unclear. Still, Stalnaker countered with claiming purely haecceitistic differences between worlds - again a desperate move.

It seems that the argument cannot be conclusively decided; softer arguments are all there are. Again, though, one might wish to entirely avoid that gambit of ever more fine-grained propositional structure. Lewis is able to do so with his richer structure of centered worlds, whereas Stalnaker must pay for his poorer structure of doxastic possibilities by assuming sufficiently fine-grained propositions.

Of course, the four examples could acquire their full force only when we discussed them much more carefully. However, I am confident that such scrutiny would confirm the conclusions reached. They all point into the same direction. And when we take the same direction concerning our topic, then it is clear what my third argument for the intentional and against the propositional conception of content is. It is this: 
According to the propositional conception a typical piece of experience or information is that an object described in a certain way falls under a certain concept. This works provided the doxastic subject has a definite description of the relevant object. However, relative to smaller or more coarse-grained propositional or conceptual frameworks such descriptions may easily cease to exist. This is simply the effect of the coarser framework and does not depend on complicated stories about (almost) indistinguishable twins. The point of the stories about forgetting or neglecting information in my first two arguments was simply to illustrate the variation of descriptive granularity. Now, if definite descriptions get lost, the increase in information cannot be accounted for by the propositional conception in its typical way. This account is simply not invariant under the granularity of doxastic possibilities.

By contrast, the intentional conception avoids this difficulty. According to it a typical piece of evidence or information is that some concept is attached to a certain address or file card; i.e., that the object represented by that address falls under that concept. This does not depend on whether or not this address can be qualitatively distinguished from other addresses within a given conceptual framework.

As already stated, addresses or file cards are not rigid. Rarely, the information stored at them will be objectively identifying. Doxastic possibilities will usually contain different objects at the same position in their sequence of objects. However, addresses are stable or invariant across conceptual changes, refinements as well as coarsenings. This is their raison d'être. If narrow contents were just general propositions built from narrow concepts, be they linguistically expressible or not, this stability could not be achieved. Russell (1910/11) also acknowledged singular propositions as belief contents referring to objects of acquaintance. He supposed, however, this reference to be rigid (although he did not use this term); he had better assumed that it is only stable in the sense explained.

Let me summarize this section in a still more general and abstract way. Including our focal case we have five examples in which the independence of descriptive granularity seems theoretically superior to and more fruitful than the appeal to sufficiently fine-grained descriptions. This leads me to speculate about a general principle of philosophical psychology:

The Invariance Principle: The propositional attitudes, their contents, and their static and dynamic laws must be so conceived as to be invariant under 
coarse- and fine-graining of the underlying conceptual and propositional framework.

Let me emphasize that this principle is neutral with respect to the nature of possible worlds that are (part of the) doxastic possibilities making up propositions. The point is not that the possible worlds themselves may be fine- or coarsegrained, as Savage's metaphor of the grand and small worlds may suggest. This would indeed make sense only with respect to Wittgensteinian possible worlds, but not with respect to Lewisian possible worlds. One may cut objects in pieces, but one cannot coarse-grain them. The invariance principle rather alludes to coarse- and fine-graining of the propositional algebra constructed over the set of doxastic possibilities. This is well compatible with the latter being maximally specific.

I am wondering about general justifications of the invariance principle. Here, we must be content with having provided ample inductive support for it. In my case, the principle entails the intentional conception of contents, if my argument is correct. If we accept the former, we should accept the latter.

\section{Some Afterthoughts}

Accepting the intentional conception has profound consequences. In section 3 I sketched the immediate dialectical background of my thesis. Afterwards, I abstracted from it and confined myself to pure epistemology. Successfully, I hope: I have talked about belief change, more precisely about belief expansion, and about the invariance principle, but not about meaning, linguistic concepts or the like. However, if we reinstall the background and if my argument goes through as a purely epistemological one, this has clear consequences for two-dimensional semantics in its epistemological reinterpretation, and it serves as confirmation of the congruence principle. It may thus also be taken as supporting the related semantic theories by Kamp (1981) and Heim (1982).

As such it also allows alternative and perhaps more plausible accounts of the logical form of various problem cases, for instance of de re belief ascriptions or of the puzzle of intentional identity in so-called Hob-Nob sentences created by 
Geach (1967). ${ }^{19}$ Quine has repeatedly reminded us, e.g. in $(1960, \S 32)$ that there are not only propositional, but also objectual attitudes like seeking, hunting, thinking of somebody. He tended to translate them into propositional attitudes, but it seems that within the intentional conception they can be taken for what they are.

Indeed, the implication is a more fundamental one, I think. The intentional conception appears to undermine the so-called context principle, i.e., the principle of the primacy of sentence meaning over word meaning. Frege already put it thus: "It is only in the context of a sentence that a word has a meaning" (1984, § 62). This principle came to play a prominent role in the philosophy of language. It did so in Quine's theory of meaning and translation, where meaning is primarily a matter of items capable of direct confrontation with experience, i.e., of observation sentences and more holistic theoretical constructions (cf. Quine 1960, ch. 12). The principle occurs in Davidson's theory of interpretation that makes essential use of the principle of charity and thus constructs the meanings of expressions (of a subject or a community) with an eye on the truth of the beliefs expressed by utterances of complete sentences (cf. Davidson 1984, ch. 2 and 9-11). The context principle also inspired various forms of skepticism, e.g., Quine's thesis of the indeterminacy of translation one version of which is basically the thesis of the inscrutability of reference (cf. Quine 1960, ch. 2), and several proposals in its wake (e.g., Putnam 1980). Ultimately, the principle and its applications rest on the assumption that doxastic attitudes are propositional attitudes the content of which can be only judged as true or false. By contrast, the intentional conception allows us to also consider the reference or, in Kamp's terms, external anchoring of the addresses or file cards figuring in doxastic possibilities. Therefore, philosophical accounts that rest on the context principle seem in urgent need of reconsideration.

This applies in particular to the account of meaning developed by Grice (1967); he as well relies upon the principle of the primacy of sentence meaning. Burge (1979, p. 109) already remarked that his anti-individualistic conception of the attitudes undermines the reductive Gricean program (cf. also Spohn 2003), and Schiffer, once a dedicated defender of Gricean intention-based semantics, devotes his whole (1987) to demolish this approach. This paper did not attempt to argue with such anti-individualistic tendencies, though it confessed its individualistic spirit. In any case, the need to reconsider the Gricean program and to restate its

\footnotetext{
${ }^{19}$ I agree with the account given by Kamp (1984/85, sect. VII, and 1990, sect. 5), where the central notion is that of sharing a discourse referent.
} 
defeasible parts in the light of the intentional conception of contents seems obvious.

These remarks could give only a few hints, not more. How exactly the intentional conception bears out these suggestions is another issue. But if only half of these remarks hold good, this would strongly underscore the relevance of the thesis defended here, beyond the importance it has in itself.

\section{Bibliography}

Armstrong, D. (1997), A World of States of Affairs, Cambridge: Cambridge University Press.

Barwise, J., J. Perry (1981), “Situations and Attitudes”, Journal of Philosophy 78, 668-691.

Barwise, J., J. Perry (1983), Situations and Attitudes, Cambridge, Mass.: MIT Press.

Bealer, G. (1982), Quality and Concept, Oxford: Oxford University Press.

Beckermann, A. (1996), “Is There a Problem About Intentionality?” Erkenntnis 45, 1-23.

Brentano, F. (1874/1973), Psychologie vom empirischen Standpunkt, Leipzig: Duncker \& Humblot 1874, engl. translation: Psychology from an Empirical Standpoint, London: Routledge \& Kegan Paul 1973.

Burge, T. (1979), "Individualism and the Mental”, in: P.A. French, T.E. Uehling jr., H.K. Wettstein (eds.), Midwest Studies in Philosophy IV, Metaphysics, Minneapolis: University of Minnesota Press, pp. 73-121.

Carnap, R. (1947), Meaning and Necessity, Chicago: University Press, 2nd ed. 1956.

Castañeda, H.-N. (1966), “'He': A Study in the Logic of Self-Consciousness”, Ratio 8, 130-157.

Chalmers, D.J. (1996), The Conscious Mind, Oxford: Oxford University Press.

Chalmers, D.J. (2006), "The Foundations of Two-Dimensional Semantics", in: M. GarcíaCarpintero, J. Macià (eds.), Two-Dimensional Semantics, Oxford: Clarendon Press, pp. 55-140.

Davidson, D. (1984), Inquiries into Truth and Interpretation, Oxford: University Press.

Evans, G. (1980), “Pronouns”, Linguistic Inquiry 11, 337-362.

Fishburn, P.C. (1964), Decision and Value Theory, New York: Wiley.

Fodor, J.A. (1990), A Theory of Content and Other Essays, Cambridge, Mass.: MIT Press.

Frege, G. (1884), Die Grundlagen der Arithmetik, German-English ed.: The Foundations of Arithmetic, Oxford: Blackwell 1959.

Frege, G. (1918), “Der Gedanke. Eine logische Untersuchung”, Beiträge zur Philosophie des deutschen Idealismus 1, 58-77; English translation: "Thought”, in: M. Beaney (ed.), The Frege Reader, Oxford: Blackwell 1997, pp. 325-345.

Geach, P.T. (1967), “Intentional Identity”, Journal of Philosophy 74, 627-632.

Grice, H.P. (1957), “Meaning”, Philosophical Review 66, 377-388.

Haas-Spohn, U. (1995), Versteckte Indexikalität und subjektive Bedeutung, Berlin: AkademieVerlag.

Haas-Spohn, U., W. Spohn (2001), “Concepts Are Beliefs About Essences”, in: A. Newen, U. Nortmann, R. Stuhlmann-Laeisz (eds.), Building on Frege. New Essays on Sense, Content, and Concept, Stanford: CSLI Publications, pp. 287-316.

Heim, I. (1982), The Semantics of Definite and Indefinite Noun Phrases, Ph.D. Dissertation, University of Massachusetts, published as Paper No. 73 of the SFB 99, University of Konstanz. 
Hintikka, J. (1962), Knowledge and Belief, Ithaca, N.Y.: Cornell University Press.

Jackson, F. (1998), From Metaphysics to Ethics, Oxford: Clarendon Press.

Jeffrey, R.C. (1965), The Logic of Decision. Chicago: University Press, 2nd ed. 1983.

Kamp, H. (1981), “A Theory of Truth and Semantic Representation”, in: J. Groenendijk, T. Janssen, M. Stokhof (eds.), Formal Methods in the Study of Language, Amsterdam: Amsterdam Centre, pp. 277-322.

Kamp, H. (1984/85), "Content, Thought, and Communication", Proceedings of the Aristotelian Society, New Series 85, 239-261.

Kamp, H. (1990), "Prolegomena to a Structural Account of Belief and Other Attitudes", in: C.A. Anderson, J. Owens (eds.), Propositional Attitudes. The Role of Content in Logic, Language, and Mind, Stanford: CSLI-Lecture Notes No. 20, pp. 27-90.

Kamp, H., U. Reyle (1993), From Discourse to Logic. Introduction to Modeltheoretic Semantics of Natural Language, Formal Logic and Discourse Representation Theory, Dordrecht: Kluwer.

Kant, I. (1781/87), Kritik der reinen Vernunft, english translation: Critique of Pure Reason, London: Macmillan 1929.

Kaplan, D. (1969), “Quantifying In”, in: D. Davidson, J. Hintikka (eds.), Words and Objections, Dordrecht: Reidel, pp. 206-242.

Kaplan, D. (1977), "Demonstratives. An Essay on the Semantics, Logic, Metaphysics, and Epistemology of Demonstratives and Other Indexicals", manuscript; published in: J. Almog et al. (eds.), Themes from Kaplan, Oxford: Oxford University Press 1989, pp. 481-563.

Kaplan, D. (1989), “Afterthoughts”, in: J. Almog et al. (eds.), Themes from Kaplan, Oxford: Oxford University Press, pp. 565-614.

Karttunen, L. (1969), "Discourse Referents", manuscript; published in: J.D. McCawley (ed.), Syntax and Semantics, vol. 7: Notes from the Linguistic Underground, New York, Academic Press 1976, pp. 363-385.

Kemmerling, A. (1990), “Genau dieselbe Überzeugung”, in: Intentionalität und Verstehen, ed. by the Forum für Philosophie in Bad Homburg, Frankfurt a.M., pp. 153-196.

Kripke, S. (1972), "Naming and Necessity”, in: D. Davidson, G. Harman (eds.), Semantics of Natural Language, Dordrecht: Reidel, pp. 253-355, 763-769; ext. ed. Oxford: Blackwell 1980.

Kripke, S. (1979), “A Puzzle About Belief”, in: A. Margalit (ed.), Meaning and Use, Dordrecht: Reidel, pp. 239-283.

Levi, I. (1967), "Probability Kinematics", British Journal for the Philosophy of Science 18, 197209.

Lewis, D. (1979), “Attitudes De Dicto and De Se”, Philosophical Review 88, 513-543; with postscripts in: D. Lewis, Philosophical Papers, Vol. I, Oxford: University Press 1983, pp. 133-156.

Lewis, D. (1980). “Index, Context, and Content”, in: S. Kanger, S. Öhman (eds.), Philosophy and Grammar, Dordrecht: Reidel, pp. 79-100.

Lewis, D. (1986a), On the Plurality of Worlds, Oxford: Blackwell.

Lewis, D. (1986b), "Postscripts to 'Causation"”, in: D. Lewis, Philosophical Papers, vol. II, Oxford: Oxford University Press, pp. 172-213.

Lewis, D. (2000), “Causation as Influence”, Journal of Philosophy, 97, 182-197.

MacKay, T., M. Nelson (2005), "Propositional Attitude Reports", Stanford Encyclopedia of Philosophy, http://plato.stanford.edu/

Maier, E. (2006), Belief in Context. Towards a Unified Semantics of de re and de se Attitude Reports, Ph.D. Thesis, Universiteit Nijmegen.

Montague, R. (1974), Formal Philosophy, New Haven: Yale University Press.

Perry, J. (1979), “The Problem of the Essential Indexical”, Noûs 13, 3-21.

Perry, J. (1980), “A Problem About Continued Belief”, Pacific Philosophical Quarterly 61 (1980), 317-332. 
Putnam, H. (1975), “The Meaning of 'Meaning,”, in: H. Putnam, Mind Language, and Reality. Philosophical Papers, Vol. 2, Cambridge: Cambridge University Press, pp. 215-271.

Putnam, H. (1980), "Models and Reality", Journal of Symbolic Logic 45, 464-482; also in: H. Putnam, Realism and Reason. Philosophical Papers, Vol. 3, Cambridge: University Press 1983, pp. 1-25.

Quine. W.V.O. (1956), “Quantifiers and Propositional Attitudes”, Journal of Philosophy 53, 177187.

Quine, W.V.O. (1960), Word and Object, Cambridge, Mass.: MIT Press.

Russell, B. (1910/11), "Knowledge by Acquaintance and Knowledge by Description", Proceedings of the Aristotelian Society 11, 108-128; also in: B. Russell, Mysticism and Logic and Other Essays, London: George Allen \& Unwin 1963, pp. 152-167.

Russell, B. (1918/19), “The Philosophy of Logical Atomism”, The Monist 28 (1918), 495-527, and 29 (1919) 32-63, 190-222, 345-380; also in: B. Russell, Logic and Knowledge, ed. by R.C. Marsh, London: George Allen \& Unwin 1956, pp. 177-281.

Salmon, W.C. (1980), "Probabilistic Causality", Pacific Philosophical Quarterly 61, 50-74.

Savage, L.J. (1954), The Foundations of Statistics, New York: Wiley, 2nd ed. 1972.

Schiffer, S. (1987), Remnants of Meaning, Cambridge, Mass.: MIT Press.

Schlenker, P. (1999), Propositional Attitudes and Indexicality. A Cross-Categorial Approch, Ph.D. Dissertation, MIT.

Spohn, W. (1978): Grundlagen der Entscheidungstheorie, Kronberg/Ts.: Scriptor; out of print, pdf-version at: http://www.uni-konstanz.de/FuF/Philo/Philosophie/Mitarbeiter/spohn.shtml.

Spohn, W. (1982), "How to Make Sense of Game Theory", in: W. Stegmüller, W. Balzer, W. Spohn (eds.), Philosophy of Economics, Berlin: Springer, pp. 239-270; reprinted in: Y. Varoufakis, A. Housego (eds.), Game Theory: Critical Concepts in the Social Sciences, Vol. IV, Discontents, London: Routledge 2001, pp. 213-241.

Spohn, W. (1983), Eine Theorie der Kausalität, unpublished Habilitationsschrift, University of Munich.

Spohn, W. (1996), "Über die Gegenstände des Glaubens", in: G. Meggle (Hg.), Proceedings des 2. Kongresses der Gesellschaft für Analytische Philosophie, de Gruyter, Berlin.

Spohn, W. (1998), "The Intentional versus the Propositional Conception of the Objects of Belief", in: C. Martinez, U. Rivas, L. Villegas-Forero (eds.), Truth in Perspective. Recent Issues in Logic, Representation and Ontology, Aldershot: Ashgate, pp. 271-291.

Spohn, W. (2003), "Burge macht uns weis: ein Zirkel bei Grice”, in: U. Haas-Spohn (ed.), Intentionalität zwischen Subjektivität und Weltbezug, Paderborn: Mentis, pp. 137-143.

Spohn, W. (2006), “Causation: An Alternative”, British Journal for the Philosophy of Science 57, 93-119.

Stalnaker, R.C. (1978), “Assertion”, in: P. Cole (ed.), Syntax and Semantics Vol. 9: Pragmatics, New York: Academic Press, pp. 315-332.

Stalnaker, R.C. (1981), "Indexical Belief”, Synthese 49, 129-151.

Zimmermann, T.E. (1999), "Remarks on the Epistemic Rôle of Discourse Referents", in: L.S. Moss, J. Ginzburg, M. de Rijke (eds.), Logic, Language, and Computation, vol. II, Stanford: CSLI Publications, pp. 346-368, also in: H. Kamp, B. Partee (eds.), Context-Dependence in the Analysis of Linguistic Meaning, Amsterdam: Elsevier 2004, pp. 521-537. 